\begin{tabular}{|c|l|}
\hline Title & Crystal structure and superconductive characteristics of Nb0.89A IO.11 oxynitrides \\
\hline Author(s) & Ohashi, Yoshio; Motohashi, Teruki; Masubuchi, Yuji; Kikkawa, Shinichi \\
\hline Citation & $\begin{array}{l}\text { Journal of Solid State Chemistry, 183(7), 1710-1714 } \\
\text { https:/doi.org/10.1016/.jssc.2010.05.023 }\end{array}$ \\
\hline Issue Date & 2010-07 \\
\hline Doc URL & http://hdl.handle.net/2115/43281 \\
\hline Type & article (author version) \\
\hline File Information & JSSC183-7_1710-1714.pdf \\
\hline
\end{tabular}

Instructions for use 
Journal of Solid State Chemistry 183 (2010) 1710-1714.

\title{
Crystal structure and superconductive characteristics of
}

$$
\mathrm{Nb}_{0.89} \mathrm{Al}_{0.11} \text { oxynitrides }
$$

\author{
Yoshio Ohashi, Teruki Motohashi,* Yuji Masubuchi, and Shinichi Kikkawa \\ Graduate School of Engineering, Hokkaido University, Sapporo 060-8628, Japan
}

The crystal structure and superconductive characteristics of the niobium-aluminum oxynitrides were investigated. Single-phase products were successfully obtained starting from a cation ratio of $\mathrm{Nb}_{0.89} \mathrm{Al}_{0.11}$. The as-nitrided product crystallized in a cation-deficient rock-salt type structure with a chemical formula of $\left(\mathrm{Nb}_{0.60} \mathrm{Al}_{0.08} \square_{0.32}\right)\left(\mathrm{O}_{0.21} \mathrm{~N}_{0.79}\right)$, while annealing at $1773 \mathrm{~K}$ under a nitrogen pressure of $0.5 \mathrm{MPa}$ led to a highly crystallized product with a simple rock-salt type structure represented as $\left(\mathrm{Nb}_{0.89} \mathrm{Al}_{0.11}\right)\left(\mathrm{O}_{0.17} \mathrm{~N}_{0.85}\right)$. Upon post-annealing, both the critical temperature $\left(T_{\mathrm{c}}\right)$ and the superconductive volume fraction $\left(V_{\mathrm{SC}}\right)$ of the oxynitride were significantly enhanced from $T_{\mathrm{C}} \approx 7$ $\mathrm{K}$ and $V_{\mathrm{SC}}=23 \%$ for the as-nitrided product to $T_{\mathrm{C}}=17.3 \mathrm{~K}$ and $V_{\mathrm{SC}}=91 \%$ for the post-annealed product.

Keywords:

niobium-aluminum oxynitrides, crystal structure, superconductivity, structural transformation

*Corresponding author

Teruki Motohashi

Graduate School of Engineering, Hokkaido University

N 13, W 8, Kita-ku, Sapporo 060-8628, Japan

E-mail address: t-mot@eng.hokudai.ac.jp

Tel: +81(0)11 7066741 Fax: +81(0)11 7066740 


\section{Introduction}

Nitrides and oxynitrides are materials with a variety of unique properties that have attracted increased interest for new applications and scientific investigations. Among the attractive functions of nitrides, superconductivity has always received much attention. Many superconductive nitrides have been discovered and extensively studied. In particular, niobium-based nitrides have been highlighted, due to their high critical temperatures $\left(T_{\mathrm{c}}\right)$. Niobium nitrides are known to crystallize in various structures having different $T_{\mathrm{C}}$ values, depending on the $\mathrm{Nb} / \mathrm{N}$ ratio. The niobium-rich phase $\alpha-\mathrm{NbN}_{z}(0 \leq \mathrm{z} \leq 0.40)$ exhibits superconductivity with $T_{\mathrm{c}}$ ranging from 4.0 to $9.2 \mathrm{~K}$ (bcc) $[1,2]$. The $\beta-\mathrm{Nb}_{2} \mathrm{~N}$ (hexagonal $\mathrm{Fe}_{2} \mathrm{~N}$-type) and $\gamma-\mathrm{Nb}_{4} \mathrm{~N}_{3}$ (tetragonal nitrogen-deficient rock-salt type) phases are superconductors with $T_{\mathrm{c}}=3.8-8.6 \mathrm{~K}$ and $12-15 \mathrm{~K}$, respectively [3-6]. The $\delta$-NbN phase possesses a cubic rock-salt type structure and exhibits the highest $T_{\mathrm{c}}$ value (15-17.3 $\mathrm{K}$ ) of the niobium-nitrogen binary systems [4,7-10]. Nitrogen-rich phases have also been reported, such as hexagonal $\mathrm{Nb}_{5} \mathrm{~N}_{6}$ and tetragonal $\mathrm{Nb}_{4} \mathrm{~N}_{5}\left(T_{\mathrm{C}}=8.5 \mathrm{~K}\right)[11,12]$. It was suggested that the local environment around niobium (e.g. coordination number and the interatomic distance between $\mathrm{Nb}$ and $\mathrm{N}$ ) plays an important role in the $T_{\mathrm{c}}$ value. Oxynitrides, such as $\delta-\mathrm{Nb}(\mathrm{O}, \mathrm{N})$ and $\varepsilon-\mathrm{Nb}(\mathrm{O}, \mathrm{N})$, have been also reported and their structures are similar to the corresponding nitrides [13,14]. All of the known niobium nitride/oxynitride superconductors are most likely of Bardeen-Cooper-Schrieffer (BCS) type, as already established for the $\delta$-NbN phase $[15,16]$.

Recently, we have reported the synthesis of a novel niobium-aluminum oxynitride through a citrate precursor route [17]. The crystal structure was analyzed by Rietveld refinement using powder X-ray diffraction (XRD) and chemical analysis data to be a rock-salt type with a nominal composition of $\left(\mathrm{Nb}_{0.56} \mathrm{Al}_{0.44}\right)\left(\mathrm{O}_{0.38} \mathrm{~N}_{0.37} \square_{0.25}\right)$; therefore, the oxynitride was assumed to correspond to an Al-for-Nb/O-for-N co-substituted derivative of the cubic $\delta$-NbN. The as-nitrided product had poor 
crystallinity without $\mathrm{Nb} / \mathrm{Al}$ and $\mathrm{O} / \mathrm{N}$ ordering. Electrical resistivity and magnetic susceptibility measurements indicated that the product was a new superconductor with $T_{\mathrm{C}} \approx 10 \mathrm{~K}$ and superconductive volume fraction $\left(V_{\mathrm{SC}}\right)$ of $3.2 \%$. It also appeared that thermal annealing at $1373 \mathrm{~K}$ in an evacuated silica tube led to improved crystallinity of the product with a small amount of impurities such as $\alpha^{-} \mathrm{Al}_{2} \mathrm{O}_{3}$, accompanied by enhancements in both $T_{\mathrm{c}}$ and $V_{\mathrm{SC}}$ of $15 \mathrm{~K}$ and $32 \%$, respectively. The crystal structure and chemical composition of the new superconductor should have been refined by taking into account the improved crystallinity from post-annealing; however, detailed characterizations could not be made, because the post-annealed product was contaminated with small amounts of unidentified secondary phases that were segregated from $\left(\mathrm{Nb}_{0.56} \mathrm{Al}_{0.44}\right)\left(\mathrm{O}_{0.38} \mathrm{~N}_{0.37} \square_{0.25}\right)$ during annealing.

In the present study, further annealing at higher temperatures was performed to obtain pure and well-crystallized $\mathrm{Nb}-\mathrm{Al}$ oxynitride by adjusting the starting $\mathrm{Nb} / \mathrm{Al}$ ratio. Single-phase as-nitrided and post-annealed products of the $\mathrm{Nb}-\mathrm{Al}$ oxynitride were prepared at a cation ratio of $\mathrm{Nb}_{0.89} \mathrm{Al}_{0.11}$ and their crystal structure was refined by XRD and neutron diffraction (ND) analyses. The superconductive characteristics of these products are discussed on the basis of the refined crystal structure.

\section{Experimental}

Polycrystalline samples of the $\mathrm{Nb}-\mathrm{Al}$ oxynitride were prepared by ammonolysis through a citrate precursor route. $\mathrm{NbCl}_{5}$ (Sigma-Aldrich, >99.9\%) and $\mathrm{AlCl}_{3} \cdot 6 \mathrm{H}_{2} \mathrm{O}$ (Wako Pure Chemicals, 99.0\%) with molar ratios of $1-x: x(x=0,0.25$, and 0.5$)$ were dissolved in $20 \mathrm{~mL}$ of anhydrous ethanol in which an equimolar amount of citric acid (Wako Pure Chemicals, 98.0\%) was added as a complexing 
agent. The solution was heated and stirred on a hot plate to promote polymerization. The resultant viscous gel was then pre-fired in air at $623 \mathrm{~K}$ for $1 \mathrm{~h}$, resulting in an amorphous oxide precursor, which was then ground, placed on an alumina boat, and set in a silica tube furnace with an internal diameter of $44 \mathrm{~mm}$. The ammonolysis reaction was carried out under flowing ammonia (Sumitomo Seika Chemicals, 99.9\%) of $50 \mathrm{~mL} / \mathrm{min}$ at $1273 \mathrm{~K}$ for $10 \mathrm{~h}$. After the ammonolysis reaction, the sample was cooled to room temperature at a rate of $3 \mathrm{~K} / \mathrm{min}$. Residual ammonia in the silica tube was purged at room temperature with flowing nitrogen gas. The as-nitrided products thus obtained were placed in a BN crucible and post-annealed at $1773 \mathrm{~K}$ for $3 \mathrm{~h}$ under a nitrogen pressure of $0.5 \mathrm{MPa}$ using a graphite furnace (High Multi 500; Fuji Dempa Kogyo).

The as-nitrided and post-annealed products were characterized using XRD, ND, chemical analysis and magnetic susceptibility measurements. XRD patterns were collected using a diffractometer with $\mathrm{Cu} \mathrm{K}_{\alpha}$ radiation (Ultima IV, Rigaku) over the $2 \theta$ angular range of 5.0-90.0 ${ }^{\circ}$ with a step size of $0.02^{\circ}$. ND measurements were carried out with a high resolution powder diffractometer (HRPD; HERMES, Institute for Materials Research, Tohoku University) installed at the JRR-3M reactor of the Japan Atomic Energy Agency (JAEA) [18]. A neutron beam with a wavelength of 0.18204(5) nm was obtained with the 331 reflection of a Ge monochromator. ND was measured over the $2 \theta$ angular range of $3.0-152.9^{\circ}$ with a step size of $0.1^{\circ}$ using approximately $3 \mathrm{~g}$ of the oxynitride product filled in a vanadium cylinder. The crystal structure of the products was refined by the Rietveld method using RIETAN2000 software [19]. The anion composition was determined using an oxygen/nitrogen combustion analyzer (EMGA-620, Horiba), which was calibrated with $\mathrm{Y}_{2} \mathrm{O}_{3}$ (Wako Pure Chemicals, $99.99 \%$, fired at $1273 \mathrm{~K}$ for $10 \mathrm{~h}$ prior to use) and $\mathrm{Si}_{3} \mathrm{~N}_{4}$ (Ceramic Society of Japan, JCRM R 003) as standard materials. Magnetic susceptibility was measured using a superconducting quantum interference device (SQUID) magnetometer (MPMS-5S, Quantum Design) in the temperature range of $2-50 \mathrm{~K}$ under a magnetic field of $5 \mathrm{mT}$. 


\section{Results and Discussion}

The Al-free as-nitrided product, $x=0$ in $\left(\mathrm{Nb}_{1-x} \mathrm{Al}_{x}\right)(\mathrm{O}, \mathrm{N})$, was a mixture of cubic $\delta-\mathrm{Nb}(\mathrm{O}, \mathrm{N})$ and hexagonal $\beta-\mathrm{Nb}_{2} \mathrm{~N}$, as shown in Fig. 1 . The $x=0.25$ product was essentially a single phase of the cubic oxynitride, while for $x=0.50$ a trace amount of $\mathrm{Al}(\mathrm{O}, \mathrm{N})$ was included as a secondary phase. Diffraction peaks of the $\mathrm{Nb}-\mathrm{Al}$ oxynitride were located at higher angles than those of Al-free $\mathrm{Nb}(\mathrm{O}, \mathrm{N})$, which implies shrinkage of the crystal lattice with Al-for-Nb substitution, probably due to the smaller atomic size of $\mathrm{Al}(125 \mathrm{pm})$ compared with $\mathrm{Nb}(145 \mathrm{pm})$ [20]. The diffraction peaks were slightly broadened in the Al-substituted products.

The Nb-Al oxynitride products were annealed at $1773 \mathrm{~K}$ under a nitrogen pressure of $0.5 \mathrm{MPa}$. The crystallinity of the post-annealed products was significantly improved, as shown in Fig. 2 . The Al-free $(x=0)$ product was pure $\delta-\mathrm{Nb}(\mathrm{O}, \mathrm{N})$ and the hexagonal $\beta-\mathrm{Nb}_{2} \mathrm{~N}$ phase totally disappeared, which corresponds to the previous report that $\beta-\mathrm{Nb}_{2} \mathrm{~N}$ readily transforms into $\delta$-NbN upon high-temperature treatment under a nitrogen pressure [7]. The post-annealed $x=0.25$ and 0.50 products were mainly the cubic Nb-Al oxynitride with a small amount of impurities such as $\alpha-\mathrm{Al}_{2} \mathrm{O}_{3}$ and $\mathrm{NbO}_{2}$ which were segregated from the $\mathrm{Nb}-\mathrm{Al}$ oxynitride phase. These impurities did not disappear upon further heat treatment due to the narrower $\mathrm{Al}$ solubility limit at elevated temperatures (1773 K) with fixed oxygen and nitrogen contents.

Rietveld refinement was performed on the post-annealed $x=0.25$ product with rock-salt type structure and the cubic Fm-3m space group, as depicted in Fig. 3. The secondary phases, assigned as $\alpha-\mathrm{Al}_{2} \mathrm{O}_{3}$ (hexagonal $R-3 c$ ), $\mathrm{NbO}_{2}$ (tetragonal $P 4_{2} / m n m$ ), and $\mathrm{Al}_{5}\left(\mathrm{BO}_{3}\right) \mathrm{O}_{6}$ (orthorhombic $C m c 2_{1}$ ), 
were also included in the refinement. Aluminum borate $\left(\mathrm{Al}_{5}\left(\mathrm{BO}_{3}\right) \mathrm{O}_{6}\right)$ was formed when the segregated aluminum oxide reacted with the boric acid sintering additive in the BN crucible. Attempts to refine the XRD data always yielded unsatisfactory reliability factors when the $\mathrm{Al}$ occupancy was set to 0 at the cation site, which indicated that the $\mathrm{Nb}$ site was partially occupied by Al. Although oxygen and nitrogen are indistinguishable by XRD analysis, the cationic composition of the $\mathrm{Nb}-\mathrm{Al}$ oxynitride was refined to be $\mathrm{Nb}_{0.89} \mathrm{Al}_{0.11}$. The actual $\mathrm{Al}$ content is smaller than the nominal one $\left(\mathrm{Nb}_{0.75} \mathrm{Al}_{0.25}\right)$, presumably due to the phase segregation during the annealing procedure.

ND data for the post-annealed $x=0.25$ product was refined as shown in Fig. 4. The magnitude of the neutron scattering length differs considerably for oxygen and nitrogen (5.803 and $9.36 \mathrm{fm}$, respectively), such that determination of the $\mathrm{O} / \mathrm{N}$ occupancy ratio may be possible. In this analysis, the $\mathrm{Nb} / \mathrm{Al}$ ratio in the oxynitride was fixed at $0.89 / 0.11$, as in the XRD Rietveld refinement. The refinement led to the oxynitride as $\left(\mathrm{Nb}_{0.89} \mathrm{Al}_{0.11}\right)\left(\mathrm{O}_{0.16} \mathrm{~N}_{0.84}\right)$ with the lattice parameter $a=0.4403(1)$ $\mathrm{nm}$. No signatures of $\mathrm{Nb} / \mathrm{Al}$ and $\mathrm{O} / \mathrm{N}$ long-range orderings were apparent. The $\mathrm{Al}$ amount of 0.11 is slightly less than $1 / 2^{3}=0.125$. One eighth of the cations in the $2 \times 2 \times 2$ superlattice are $\mathrm{Al}$, which means that $\mathrm{Al}$ can be accommodated at the center of the $2 \times 2 \times 2$ superlattice. The real occupancy was slightly less than the ideal value, probably due to the reaction kinetics. The secondary phases, $\alpha-\mathrm{Al}_{2} \mathrm{O}_{3}, \mathrm{NbO}_{2}$, and $\mathrm{Al}_{5}\left(\mathrm{BO}_{3}\right) \mathrm{O}_{6}$, were taken into account and their quantities were also refined to be 10.0, 4.6, and $3.7 \mathrm{wt} \%$, respectively. With these values, the total amounts of oxygen and nitrogen are calculated to be 8.1 and 9.5 wt\%, respectively, which are in good agreement with those determined by the chemical analysis, 8.2(3) and 9.5(3) wt\%.

It is now clear that the $\mathrm{Al}$ solubility limit of the $\mathrm{Nb}-\mathrm{Al}$ oxynitride could be as small as 11 at $\%$ at $1773 \mathrm{~K}$. In fact, both of the as-nitrided and post-annealed products were successfully synthesized as pure forms when starting from a nominal Al content of $x=0.11$ as described in Figs. 5 and 6 . Table 1 
summarizes the oxygen and nitrogen contents of these $\mathrm{Nb}_{0.89} \mathrm{Al}_{0.11}$ oxynitride products. The post-annealed product has lesser amounts of oxygen and nitrogen than those of the as-nitrided product. The respective total cation and anion amounts correspond to approximately one mole (i.e. $\left.\mathrm{Nb}_{0.89} \mathrm{Al}_{0.11} \mathrm{O}_{0.17(1)} \mathrm{N}_{0.85(3)}\right)$. However the as-nitrided product has an approximately $50 \%$ anion excess when no cation deficiency is assumed (i.e. $\mathrm{Nb}_{0.89} \mathrm{Al}_{0.11} \mathrm{O}_{0.32(2)} \mathrm{N}_{1.16(3)}$ ). Since the presence of interstitial anions in the rock-salt type structure is unlikely, this result implies that the as-nitrided product crystallizes in a cation-deficient structure as $\left(\mathrm{Nb}_{0.60} \mathrm{Al}_{0.08} \square_{0.32}\right)\left(\mathrm{O}_{0.21(1)} \mathrm{N}_{0.79(2)}\right)$.

The structure of the as-nitrided product appears to be more complex than that of the simple rock-salt type. Figure 5 shows weak extra peaks at around $2 \theta=18.2,24.3,25.9$ and $53.0^{\circ}$ in addition to strong reflections of the fundamental rock-salt structure. The strong peaks and the extra weak peaks can be indexed using a tetragonal unit cell with $a=\sqrt{ }(5 / 2) a_{\mathrm{RS}}$ and $c=a_{\mathrm{RS}}$, where $a_{\mathrm{RS}}$ denotes the lattice parameter of the cubic rock-salt structure. The crystal structure is successfully refined based on the $I 4 / m$ space group, as summarized in Table 2 . The structural model is assumed to be a cation-deficient rock-salt type, which is isostructural to $\mathrm{Nb}_{4} \mathrm{~N}_{5}, \mathrm{Ti}_{4} \mathrm{O}_{5}$, and $\mathrm{Ta}_{4} \mathrm{~N}_{5}$. In this $\mathrm{Nb}_{4} \mathrm{~N}_{5}$-type structure, two different crystallographic cation sites are present, as illustrated in Fig. 7; the Wyckoff position $8 h$ is fully occupied, while the $2 a$ position is empty in the ideal case. For the present as-nitrided $\mathrm{Nb}_{0.89} \mathrm{Al}_{0.11}$ oxynitride, $\mathrm{Al}$ atoms are assumed to partially occupy the $2 a$ sites with $\mathrm{Nb}$ atoms to converge the refinement (see Table 2). The incomplete site preference on the 2a site is evident, because the extra peaks are much weaker than those expected for the ideal $\mathrm{Nb}_{4} \mathrm{~N}_{5}$-type structure. A similar cation-deficient structure was also reported for a Mn-doped Nb oxynitride, $\mathrm{Mn}_{0.54} \mathrm{Nb}_{3.07} \mathrm{~N}_{4.40} \mathrm{O}_{0.60}$, in which the strong affinity between $\mathrm{Mn}$ and $\mathrm{O}$ is believed to stabilize the anion-rich composition.

The XRD pattern for the post-annealed $\mathrm{Nb}_{0.89} \mathrm{Al}_{0.11}$ oxynitride product was readily refined, as 
represented in Fig. 6, based on the simple rock-salt type structure, assuming the composition determined by the chemical analysis. The atomic parameters and refinement details are summarized in Tables 2 and 3, respectively. The (Nb,Al)-(O,N) bond distance of $d=a / 2=0.220 \mathrm{~nm}$ is within the range of reported values for the isostructural $\mathrm{Nb}(\mathrm{O}, \mathrm{N})(0.2186-0.2216 \mathrm{~nm})[11,17]$, whereas this value is much longer than those of $0.195 \mathrm{~nm}$ for $\mathrm{Al}-\mathrm{O}$ in $\alpha-\mathrm{Al}_{2} \mathrm{O}_{3}(\mathrm{CN}=6)$ [21] and $0.193 \mathrm{~nm}$ for Al-N in AlN (CN = 4) [22]. The displacement parameter $(B)$ is larger for the $\mathrm{O} / \mathrm{N}$ site than that for the $\mathrm{Nb} / \mathrm{Al}$ site. A similar tendency was seen in the result of ND analysis on the $x=0.25$ products. This is presumably due to the fact that the $\mathrm{O} / \mathrm{N}$ bond distance is slightly shorter around the randomly distributed $\mathrm{Al}$ atoms. The $\mathrm{Al}$ atoms are not well stabilized in the rock-salt type lattice; upon high-temperature annealing under nitrogen pressure, the $\mathrm{Al}$ atoms may migrate through cation defects and $\mathrm{f} 1.5 \mathrm{O}^{2-}$ may also be replaced with $\mathrm{N}^{3-}$, leading to the change in the crystal structure from the cation-deficient form to the cation/anion stoichiometric form.

Magnetic susceptibility $(\chi)$ of the $\mathrm{Nb}_{0.89} \mathrm{Al}_{0.11}$ oxynitrides is plotted as a function of temperature in Fig. 8. The as-nitrided product $\left(\mathrm{Nb}_{0.60} \mathrm{Al}_{0.08} \square_{0.32}\right)\left(\mathrm{O}_{0.21(1)} \mathrm{N}_{0.79(2)}\right)$ exhibits large diamagnetism due to superconductivity below $T_{\mathrm{c}} \approx 7 \mathrm{~K}$. Small negative $\chi\left(\sim 10^{-3} \mathrm{emu} \mathrm{mol}^{-1} \mathrm{Oe}^{-1}\right)$ is also observed between 7 and $10 \mathrm{~K}$, which indicates the coexistence of small domains with different $T_{\mathrm{c}}$ values. From the zero-field-cooling curve, $V_{\mathrm{SC}}$ was calculated to be $23 \%$ at $2 \mathrm{~K}$. On the other hand, the post-annealed product $\mathrm{Nb}_{0.89} \mathrm{Al}_{0.11} \mathrm{O}_{0.17(1)} \mathrm{N}_{0.85(3)}$ exhibited much improved superconductive characteristics of $T_{\mathrm{C}}=17.3 \mathrm{~K}$ and $V_{\mathrm{SC}}=91 \%$. To our best knowledge, this $T_{\mathrm{c}}$ value is the highest among the known Nb-based nitrides/oxynitrides with rock-salt type structures.

The elimination of cation vacancy in post-annealing was important to improve the superconductive characteristics. Previous studies on Nb-based nitrides/oxynitrides have indicated the highest $T_{\mathrm{c}}$ value for the stoichiometric $\delta$-NbN phase, while cation-deficient compounds tend to 
exhibit lower $T_{\mathrm{c}}[11,12]$. The shorter $\mathrm{Nb}-\mathrm{O}(\mathrm{N})$ interatomic distance in the cation-deficient compounds may be one possible reason for lowering of the $T_{\mathrm{c}}$ in the BCS framework, because reduced interatomic distance usually leads to a decrease in the density of states at the Fermi level. Nevertheless, the difference in the $\mathrm{Nb}-\mathrm{O}(\mathrm{N})$ distance is too small to explain the wide variation in $T_{\mathrm{c}}$ among the Nb-based nitride/oxynitride members. On the other hand, the formal valence of niobium is calculated to be +4.25 for the as-nitrided product and +2.88 for the post-annealed one, under the assumption that the aluminum, oxygen, and nitrogen valences are $+3,-2$, and -3 , respectively. Such a large variation in the niobium valence may contribute to enhance the $T_{\mathrm{c}}$-value upon post-annealing.

The small $V_{\text {SC }}$ of $23 \%$ for the as-nitrided $\left(\mathrm{Nb}_{0.60} \mathrm{Al}_{0.08} \square_{0.32}\right)\left(\mathrm{O}_{0.21(1)} \mathrm{N}_{0.79(2)}\right)$ can be discussed based on the deteriorated superconducting path. Structural refinement revealed that the as-nitrided product contains a large amount of lattice defects at both the two cation sites. The highly cation deficient nature of the as-nitrided $\left(\mathrm{Nb}_{0.60} \mathrm{Al}_{0.08} \square_{0.32}\right)\left(\mathrm{O}_{0.21(1)} \mathrm{N}_{0.79(2)}\right)$ is evident from the poor crystallinity of the product. Such lattice defects are likely to effectively disrupt the superconductive path, resulting in a large decrease in $V_{\mathrm{SC}}$. In contrast, the post-annealed $\mathrm{Nb}-\mathrm{Al}$ oxynitride shows nearly perfect diamagnetism with a high $T_{\mathrm{c}}$ value, which implies that $\mathrm{Al}$ atoms in the crystal lattice do not have a negative impact on the superconductive characteristics of the pristine $\mathrm{Nb}$ nitride. The substituted $\mathrm{Al}$ atoms may form $\mathrm{Al}-\mathrm{O}$ pairs in the rock-salt type lattice framework, which is suggested by the similar amounts of $\mathrm{Al}$ and $\mathrm{O}$ in the oxynitride. The small size of such a pairing minimizes the scattering probability of conduction electrons; the electron density in the NbN sublattice is changed by incorporation of the Al-O pair in $\mathrm{Nb}_{0.89} \mathrm{Al}_{0.11} \mathrm{O}_{0.17} \mathrm{~N}_{0.85}$.

\section{Conclusions}

Niobium-aluminum oxynitrides were synthesized by ammonolysis of amorphous oxide 
precursors through a citrate precursor route. Single-phase products were successfully obtained starting from a cation ratio of $\mathrm{Nb}_{0.89} \mathrm{Al}_{0.11}$. The as-nitrided product crystallized in a cation-deficient rock-salt type structure with the chemical formula $\left(\mathrm{Nb}_{0.60} \mathrm{Al}_{0.08} \square_{0.32}\right)\left(\mathrm{O}_{0.21} \mathrm{~N}_{0.79}\right)$. This product exhibited superconductivity below $T_{\mathrm{c}} \approx 7 \mathrm{~K}$ with $V_{\mathrm{SC}}=23 \%$. The annealing procedure at $1773 \mathrm{~K}$ under a nitrogen pressure of $0.5 \mathrm{MPa}$ led to a highly crystallized product with a simple rock-salt type structure represented as $\left(\mathrm{Nb}_{0.89} \mathrm{Al}_{0.11}\right)\left(\mathrm{O}_{0.17} \mathrm{~N}_{0.85}\right)$. The post-annealed product showed improved superconductive characteristics with $T_{\mathrm{C}}=17.3 \mathrm{~K}$ and $V_{\mathrm{SC}}=91 \%$.

\section{Acknowledgements}

The present work was supported by Grants-in-Aid for Scientific Research (Contracts No. 19350098 and No. 21245047) from the Japan Society for the Promotion of Science. ND experiments were performed under the approval of $9876 \mathrm{~K}$. The authors are grateful to Profs. M. Wakeshima and Y. Hinatsu for their help in both the ND and magnetic susceptibility measurements. T. M. acknowledges financial support from the Global COE Program (Project No. B01: "Catalysis as the Basis for Innovation in Materials Science”) from the Ministry of Education, Culture, Sports, Science and Technology, Japan. 


\section{Reference}

[1] R. W. Guard, J. W. Savage, D. G. Swartout, Trans. Metall. Soc. AIME 239 (1967) 643-649.

[2] D. W. Deis, J. R. Gavaler, J. K. Hulm, C. K. Jones, J. Appl. Phys. 40 (1969) 2153-2155.

[3] E. F. Skelton, M. R. Skokan, E. Cukauskas, J. Appl. Cryst. 14 (1981) 51-57.

[4] J. R. Gavaler, J. K. Hulm, M. A. Jankocko, C. K. Jones, J. Vac. Sci. Tech. 6 (1969) 177-180.

[5] P. Fabbricatore, P. Fernandes, G. C. Gualco, F. Merlo, R. Musenich, R. Parodi, J. Appl. Phys. 66 (1989) 5944-5949.

[6] B. Scheerer, J. Cryst. Growth. 49 (1980) 61-66.

[7] A. V. Linde, R.-M. Marin-Ayral, D. Granier, F. Bosc-Rounessac, V.V. Grachev, Mater. Res. Bull. 44 (2009) 1025-1030.

[8] V. Buscaglia, F. Caracciolo, M.Minguzzi, R. Musenich, J. Alloys Compd. 266 (1998) 201-206.

[9] M. W. Williams, K. M. Ralls, M. R. Pickus, J. Phys. Chem. Solids 28 (1967) 333-341.

[10] K. S. Keskar, T. Yamashita, Y. Onodera, Jpn. J. Appl. Phys. 10 (1971) 370.

[11] N. Terao, J. Less-Common Met. 23 (1971) 159-169.

[12] G.Oya, Y.Onodera, J. Appl. Phys. 45 (1974) 1389-1397.

[13] G. Brauer, J. Less-Common. Met. 2 (1960) 131-137

[14] R. Roy, P. F. Carcia, R. Messier, D. Rogowski, Mater. Res. Bull. 10 (1975) 379-382.

[15] H. S. Somal, B. J. Feenstra, J. Schützmann, Jae Hoon Kim, Z. H. Barber, V. H. M. Duijn, N. T. Hien, A. A. Menovsky, Mario Palumbo, D. van der Marel, Phys. Rev. Lett. 76 (1996) 1525-1528.

[16] H. Nishihara, Y. Furutani, S. Yokota, M. Ohyanagi, Y. Kumashiro, J. Alloys Compd. 383 (2004) 308.

[17] S. Yamamoto, Y. Ohashi, Y. Masubuchi, T. Takeda, T. Motohashi, S. Kikkawa, J. Alloys Compd. 482 (2009) 160-163.

[18] K. Ohoyama, T. Kanouchi, K. Nemoto, M. Ohashi, T. Kajitani, Y. Yamaguchi, Jpn. J. Appl. 
Phys. 37 (1998) 3319-3326.

[19] F. Izumi, T. Ikeda, Mater. Sci. Forum 321-324 (2000) 198-203.

[20] J. C. Slater, J. Chem. Phys. 41 (1964) 3199-3204.

[21] P. Ballirano, R. Caminiti, J. Appl. Cryst. 34 (2001) 757-762.

[22] W. Paszkowicz, S. Podsiadlo, R. Minikayev, J. Alloys Compd. 382 (2004) 100-106. 
Table 1. Oxygen and nitrogen contents of the as-nitrided and post-annealed $\mathrm{Nb}_{0.89} \mathrm{Al}_{0.11}$ oxynitrides.

\begin{tabular}{|c|c|c|c|}
\hline \multirow{2}{*}{ Sample } & \multicolumn{2}{|c|}{ Amount / wt \% } & \multirow{2}{*}{ Composition } \\
\hline & $\mathrm{O}$ & $\mathrm{N}$ & \\
\hline As-nitrided & $4.7 \pm 0.2$ & $15.2 \pm 0.3$ & $\mathrm{Nb}_{0.89} \mathrm{Al}_{0.11} \mathrm{O}_{0.32(1)} \mathrm{N}_{1.16(2)}$ \\
\hline Post-annealed & $2.8 \pm 0.1$ & $11.9 \pm 0.4$ & $\mathrm{Nb}_{0.89} \mathrm{Al}_{0.11} \mathrm{O}_{0.17(1)} \mathrm{N}_{0.85(3)}$ \\
\hline
\end{tabular}


Table 2. Atomic parameters for the as-nitrided and post-annealed $\mathrm{Nb}_{0.89} \mathrm{Al}_{0.11}$ oxynitrides.

\begin{tabular}{ccccccc}
\hline Atom & Site & $g$ & $x$ & $y$ & $z$ & $\mathrm{~B} / 10^{-2} \mathrm{~nm}^{2}$ \\
\hline As-nitrided (I4/m) & & & & & & \\
$\mathrm{Nb} / \mathrm{Al}$ & $2 a$ & $0.48(1) / 0.45(0)$ & 0 & 0 & 0 & $0.24(7)$ \\
$\mathrm{Nb}$ & $8 h$ & 0.79 & $0.394(1)$ & $0.204(1)$ & 0 & $0.32(6)$ \\
$\mathrm{O} / \mathrm{N}(1)$ & $8 h$ & $0.16 / 0.84$ & $0.107(3)$ & $0.319(2)$ & 0 & $0.85(5)$ \\
$\mathrm{O} / \mathrm{N}(2)$ & $2 b$ & $0.16 / 0.84$ & 0 & 0 & $1 / 2$ & $0.82(5)$ \\
Post-annealed $(F m-3 m)$ & & & & & \\
$\mathrm{Nb} / \mathrm{Al}$ & $4 a$ & $0.89 / 0.11$ & 0 & 0 & 0 & $0.42(3)$ \\
O/N & $4 b$ & $0.16 / 0.84$ & $1 / 2$ & $1 / 2$ & $1 / 2$ & $1.24(2)$ \\
\hline
\end{tabular}


Table 3. Rietveld refinement details for the as-nitrided and post-annealed $\mathrm{Nb}_{0.89} \mathrm{Al}_{0.11}$ oxynitrides.

\begin{tabular}{|c|c|c|}
\hline Sample & As-nitrided & Post-annealed \\
\hline Composition & $\mathrm{Nb}_{0.60} \mathrm{Al}_{0.08} \mathrm{O}_{0.21(1)} \mathrm{N}_{0.79(2)}$ & $\mathrm{Nb}_{0.89} \mathrm{Al}_{0.11} \mathrm{O}_{0.17(1)} \mathrm{N}_{0.85(3)}$ \\
\hline Crystal system & Tetragonal & Cubic \\
\hline Space group & $I 4 / m$ & $F m-3 m$ \\
\hline$a / \mathrm{nm}$ & $0.6874(4)$ & $0.4401(2)$ \\
\hline$c / \mathrm{nm}$ & $0.4346(5)$ & \\
\hline Volume $/ \times 10^{-27} \mathrm{~m}^{3}$ & $0.2054(5)$ & $0.0852(1)$ \\
\hline$d_{\mathrm{Nb} / \mathrm{Al}-\mathrm{O} / \mathrm{N}} / \mathrm{nm}$ & $(2 \times) 0.217(0)$ & $(6 \times) 0.220$ \\
\hline & $(4 \times) 0.200(0)$ & \\
\hline \multirow[t]{4}{*}{$d_{\mathrm{Nb}-\mathrm{O} / \mathrm{N}} / \mathrm{nm}$} & $(1 \times) 0.212(0)$ & \\
\hline & $(1 \times) 0.219(0)$ & \\
\hline & $(1 \times) 0.238(0)$ & \\
\hline & $(3 \times) 0.218(0)$ & \\
\hline$R_{\mathrm{wp}}$ & 7.99 & 11.93 \\
\hline$S$ & 1.81 & 1.89 \\
\hline$Z$ & 10 & 4 \\
\hline
\end{tabular}




\section{Figure captions}

Fig. 1.

Powder XRD patterns for the as-nitrided products with nominal $\mathrm{Al}$ contents $x=0,0.25$, and 0.50 in $\left(\mathrm{Nb}_{1-x} \mathrm{Al}_{x}\right)(\mathrm{O}, \mathrm{N})$. Diffraction peaks due to secondary phases $\beta-\mathrm{Nb}_{2} \mathrm{~N}$ and $\mathrm{Al}(\mathrm{O}, \mathrm{N})$ are indicated.

Fig. 2.

Powder XRD patterns for the post-annealed products with nominal Al contents $x=0,0.25$, and 0.50 in $\left(\mathrm{Nb}_{1-x} \mathrm{Al} \mathrm{l}_{\chi}\right)(\mathrm{O}, \mathrm{N})$. Diffraction peaks due to secondary phases $\mathrm{NbO}_{2}$ and $\alpha-\mathrm{Al}_{2} \mathrm{O}_{3}$ are indicated.

\section{Fig. 3.}

Rietveld refinement of the XRD pattern for the post-annealed $\left(\mathrm{Nb}_{0.75} \mathrm{Al}_{0.25}\right)(\mathrm{O}, \mathrm{N})$ product. The secondary phases, $\alpha-\mathrm{Al}_{2} \mathrm{O}_{3}$ (hexagonal $R-3 c$ ), $\mathrm{NbO}_{2}$ (tetragonal $P 4_{2} / m n m$ ), and $\mathrm{Al}_{5}\left(\mathrm{BO}_{3}\right) \mathrm{O}_{6}$ (orthorhombic $C m c 2_{1}$ ), were also included in the refinement. The $R_{\mathrm{wp}}$ and $S$ values were $5.20 \%$ and 1.41 , respectively.

Fig. 4.

Rietveld refinement of the ND pattern for the post-annealed $\left(\mathrm{Nb}_{0.75} \mathrm{Al}_{0.25}\right)(\mathrm{O}, \mathrm{N})$ product. The secondary phases, $\alpha-\mathrm{Al}_{2} \mathrm{O}_{3}$ (hexagonal $R-3 c$ ), $\mathrm{NbO}_{2}$ (tetragonal $P 4_{2} / m n m$ ), and $\mathrm{Al}_{5}\left(\mathrm{BO}_{3}\right) \mathrm{O}_{6}$ (orthorhombic $C m c 2_{1}$ ), were also included in the refinement. The $R_{\mathrm{wp}}$ and $S$ values were $4.88 \%$ and 1.33 , respectively.

Fig. 5.

Rietveld refinement of the XRD pattern for the as-nitrided $\left(\mathrm{Nb}_{0.89} \mathrm{Al}_{0.11}\right)(\mathrm{O}, \mathrm{N})$ product. Unassigned extra peaks of the simple rock-salt structure are marked with triangles. 
Fig. 6.

Rietveld refinement of the XRD pattern for the post-annealed $\left(\mathrm{Nb}_{0.89} \mathrm{Al}_{0.11}\right)(\mathrm{O}, \mathrm{N})$ product. The refinement was carried out based on the nominal cationic ratio and the anionic composition as determined by chemical analysis.

Fig. 7.

Schematic illustration of the crystal structures of the $\mathrm{Nb}_{0.89} \mathrm{Al}_{0.11}$ oxynitrides along the [001] direction of the (a) as-nitrided, and (b) post-annealed products. The two cation sites, $2 a$ and $8 h$ Wyckoff positions, are represented by red open circles and blue spheres, respectively. Anion sites are represented by gray spheres. The solid line denotes the unit cell.

Fig. 8.

Temperature dependence of magnetic susceptibility $(\chi)$ for the (a) as-nitrided, and (b) post-annealed $\mathrm{Nb}_{0.89} \mathrm{Al}_{0.11}$ oxynitrides. 


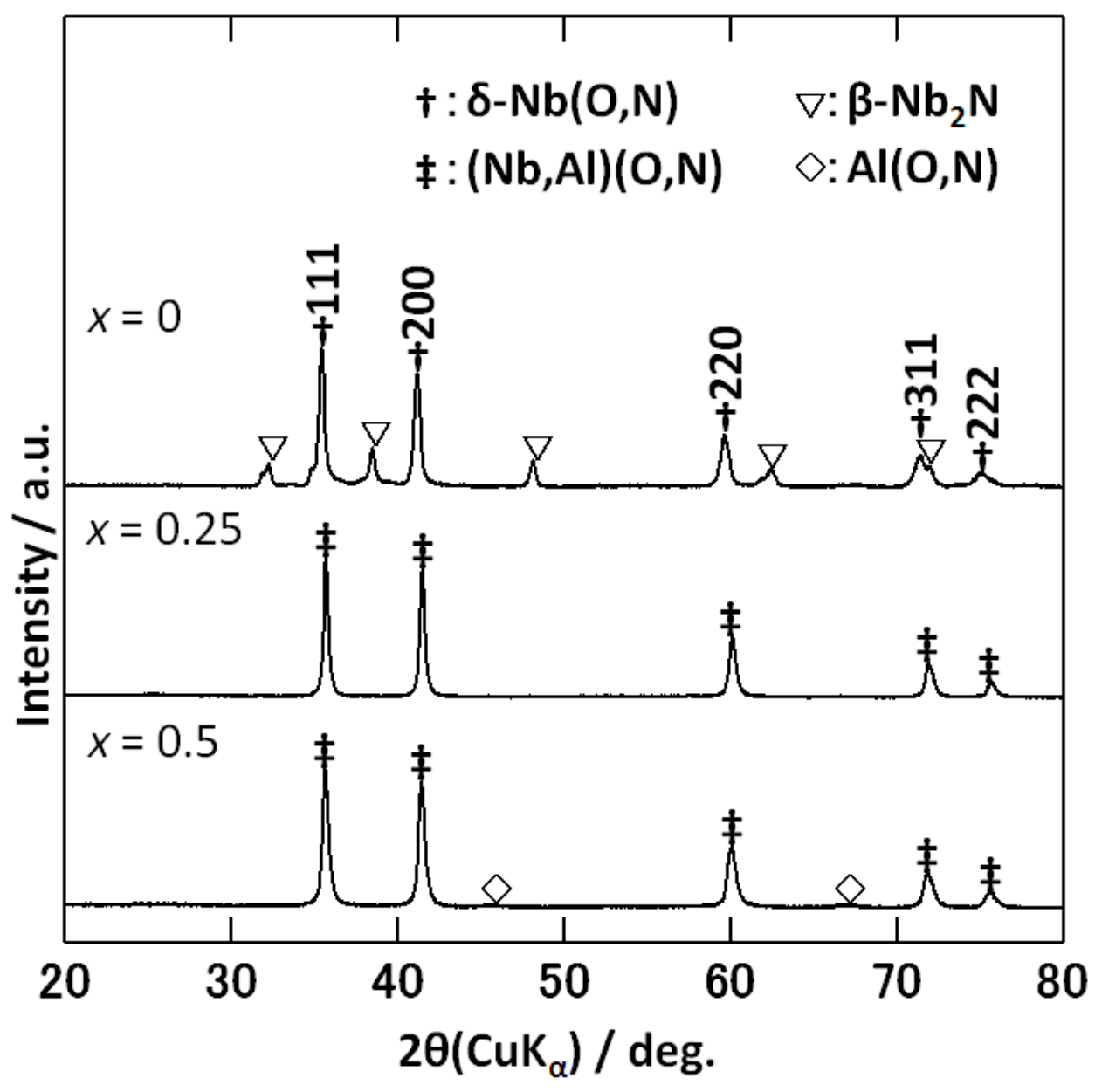

Fig. 1. Ohashi et al. 


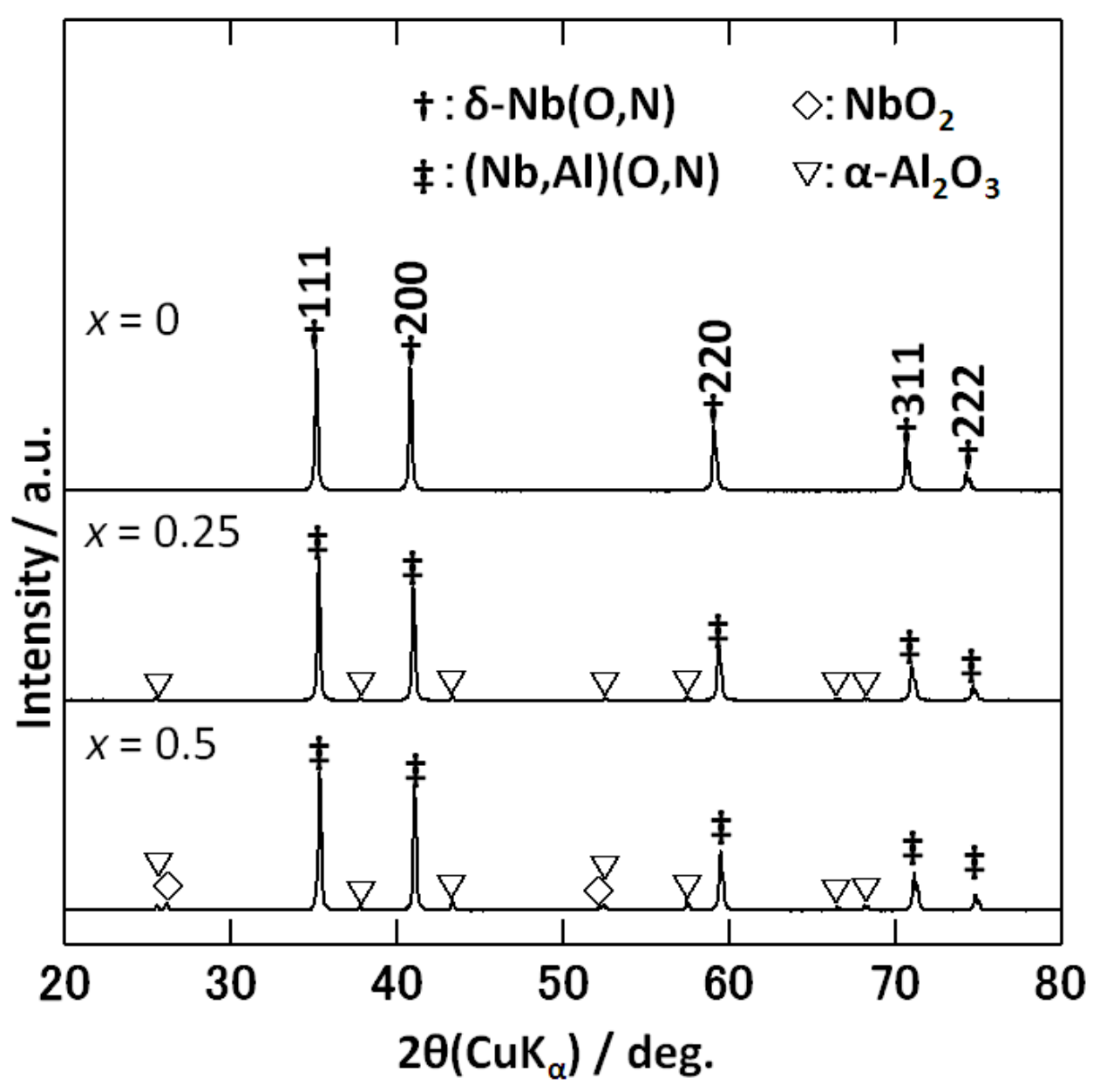

Fig. 2. Ohashi et al. 


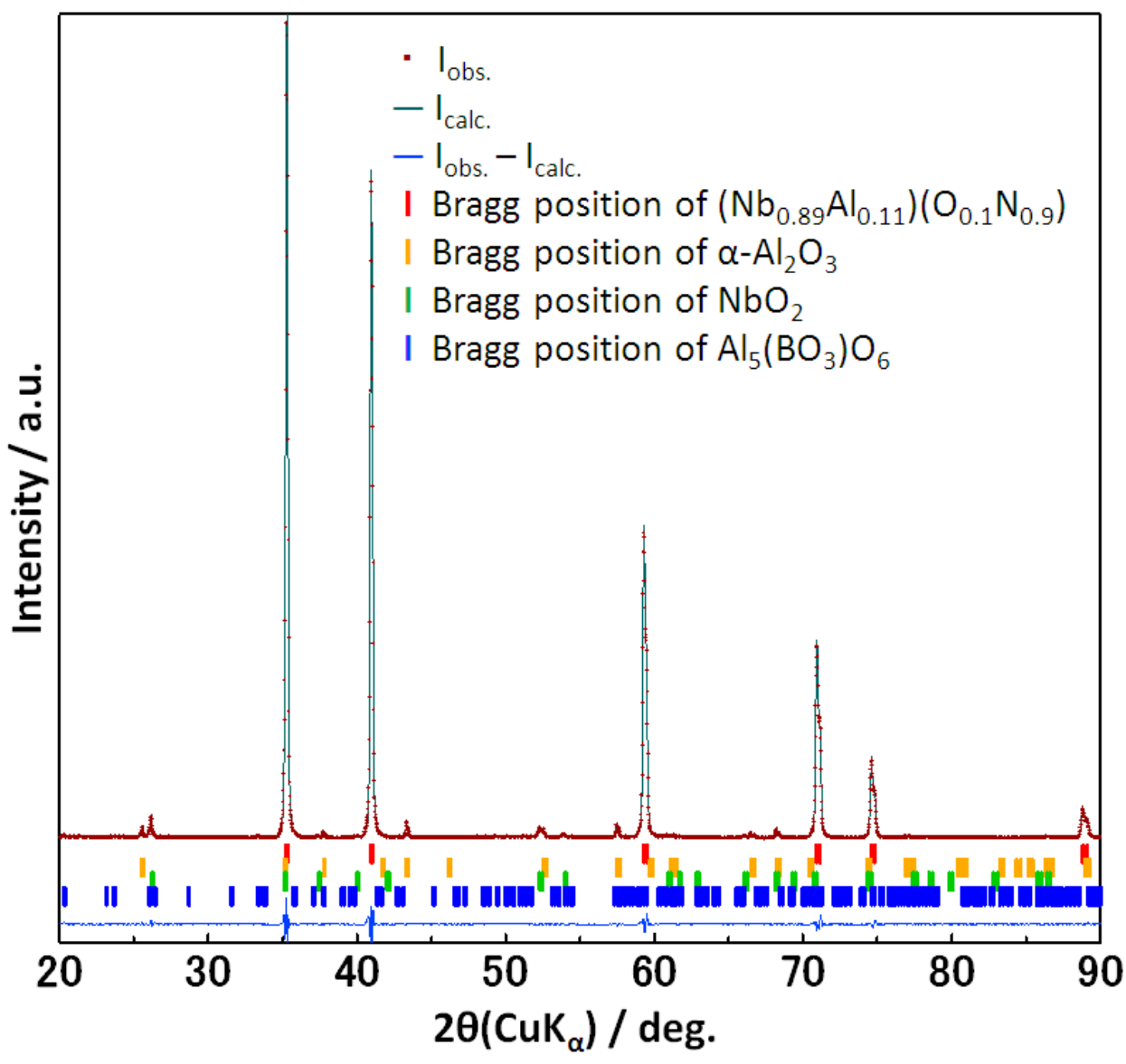

Fig. 3. Ohashi et al. 


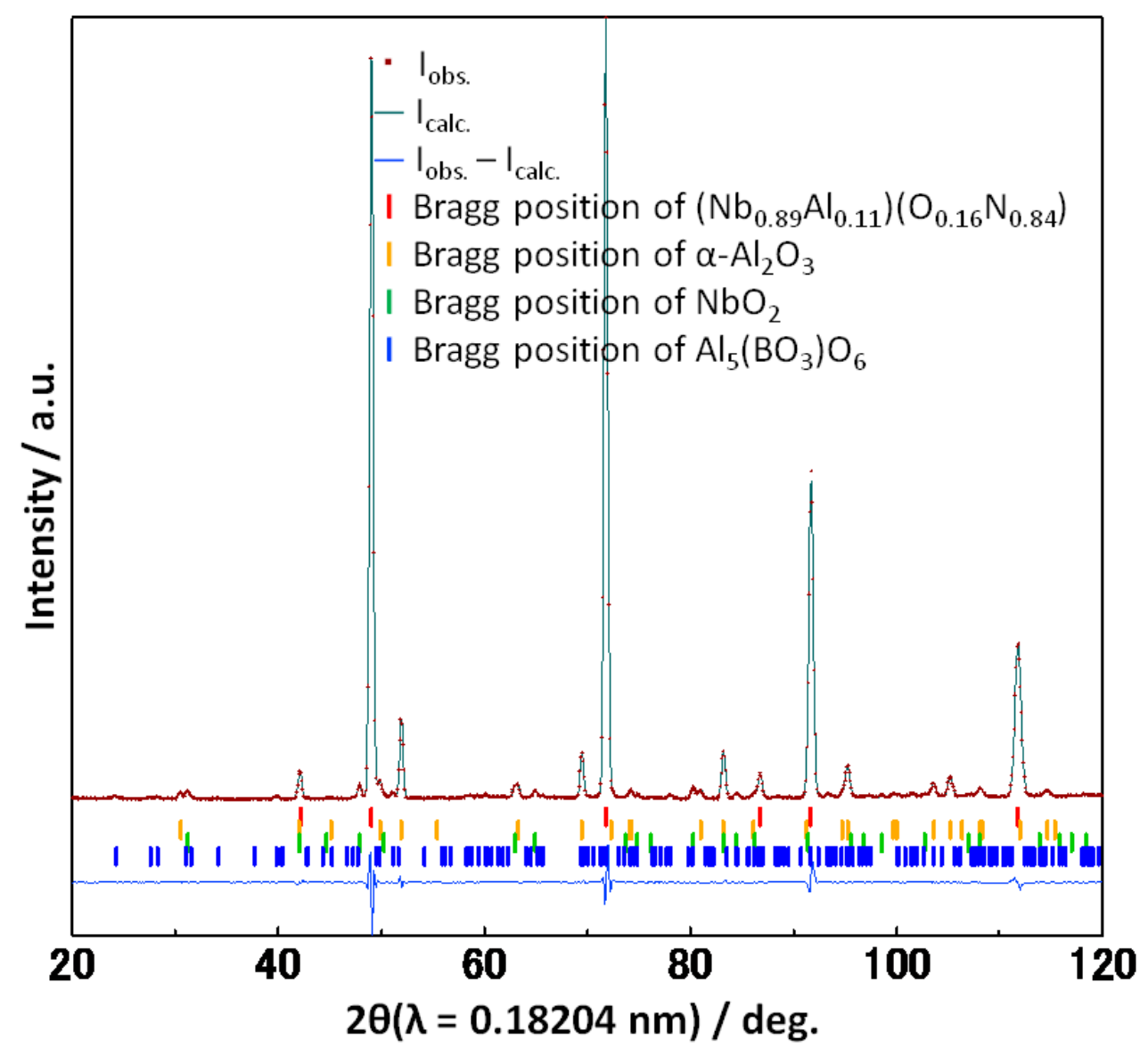

Fig. 4. Ohashi et al. 


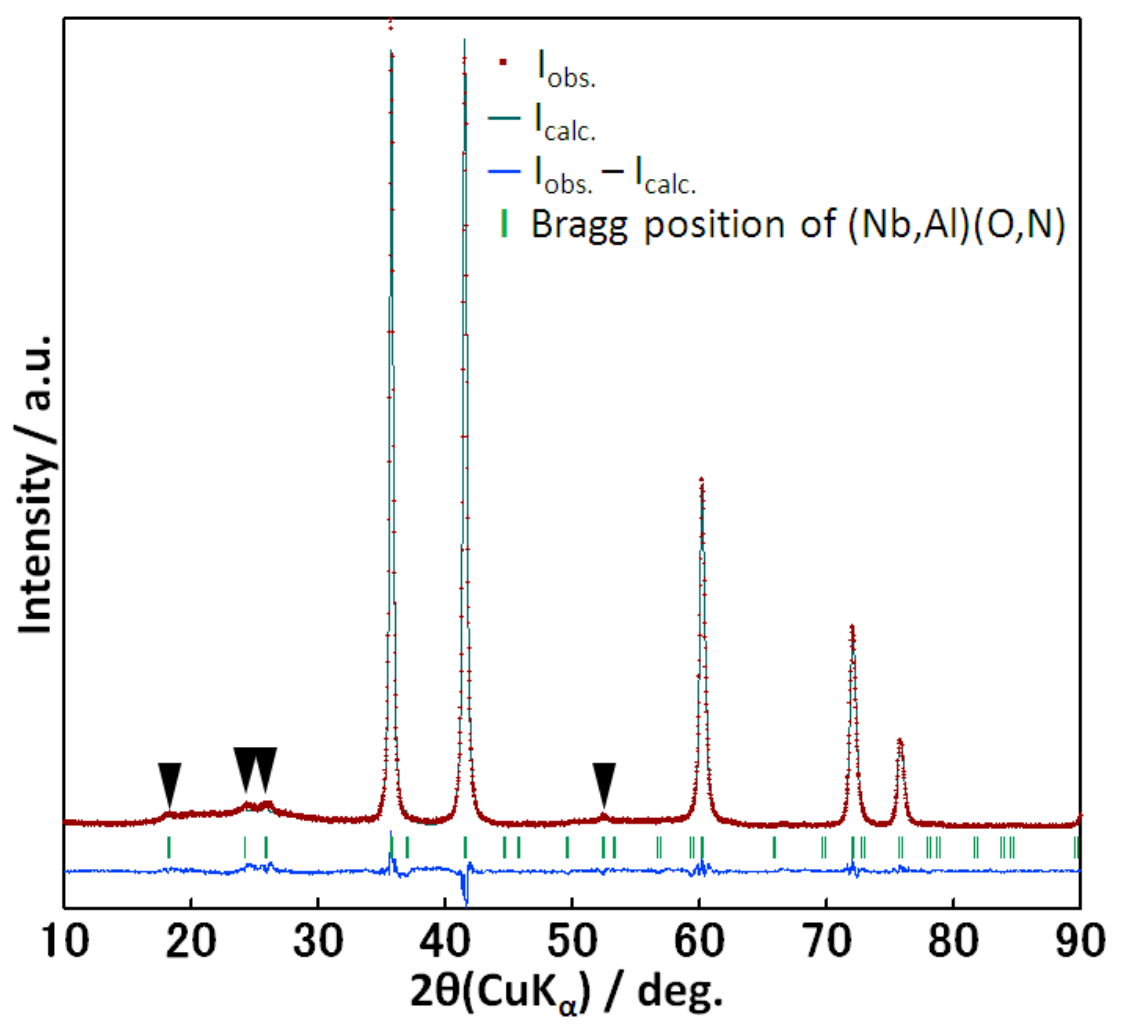

Fig. 5. Ohashi et al. 


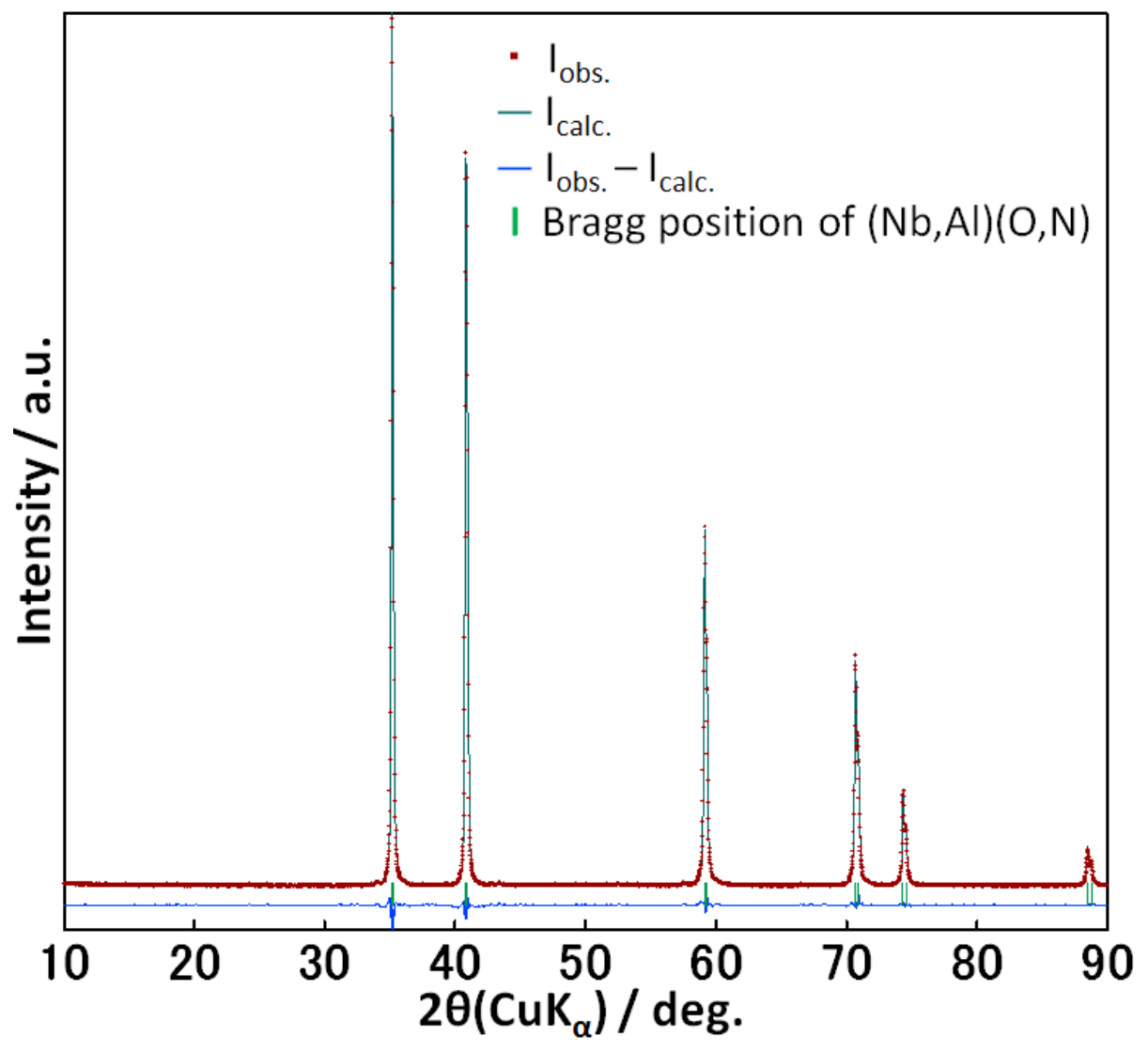

Fig. 6. Ohashi et al. 
(a)

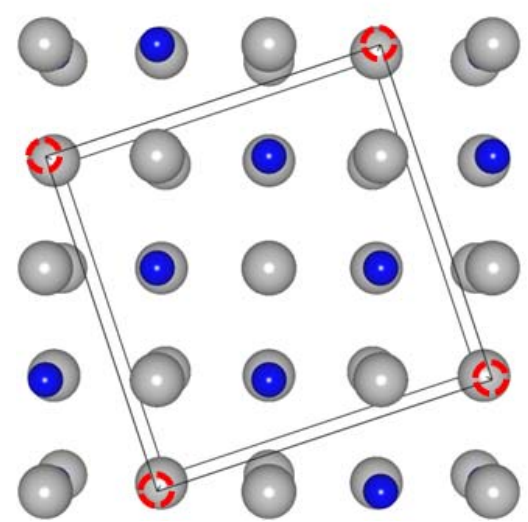

(b)

Q $\odot \circ \%$

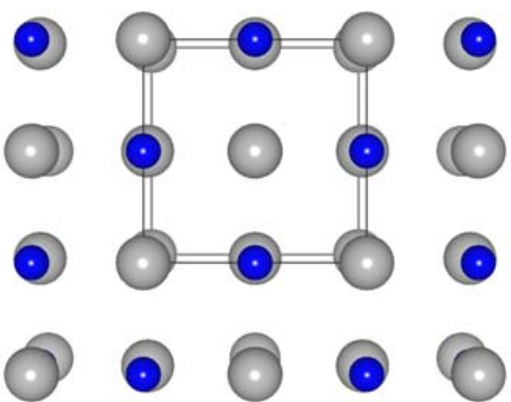

Fig. 7. Ohashi et al. 


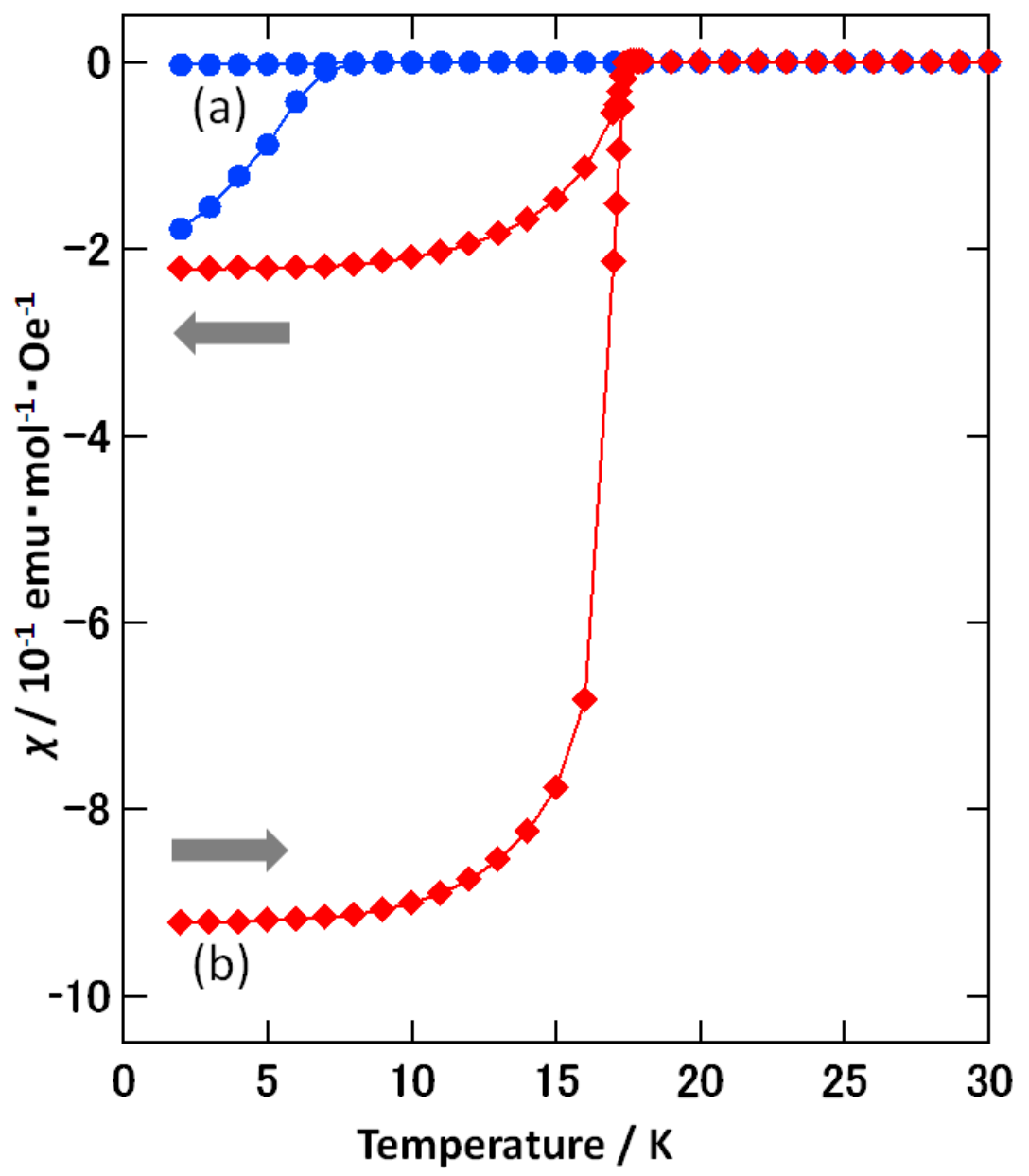

Fig. 8. Ohashi et al. 